\title{
Nurse-elderly patient communication in home care and institutional care: an explorative study
}

\author{
Wilma M. C. M. Caris-Verhallen ${ }^{\mathrm{a}, *}$, Ada Kerkstra ${ }^{\mathrm{a}}$, \\ Peter G. M. van der Heijden ${ }^{\mathrm{h}}$, Jozien M. Bensing ${ }^{\mathrm{c}}$ \\ "Department of Nursing and Caring Research, Netherlands Institute' of Primary Health Care (NIVEL), PO Box 1568. \\ 3500 BN Utrecht, The Netherlands \\ 'Department of Methodology and Statistics, University of Utrecht, Utrecht, The Netherlands \\ "Netherlands Institule of Primary Health Care, Utrecht and Department of Clinical and Health Psychology, \\ University of Utrecht. Utrecht. The Netherlands
}

Received October 1996; revised June 1997 ; accepted October 1997

\begin{abstract}
This study explores communication patterns between nurses and elderly patients in two different care settings. In a sample of 181 video-taped nursing encounters, involving 47 nurses and 109 patients, a study was made of nurse patient communication. The video recordings were observed using an adapted version of Roter's Interaction Analysis System, which yields frequencies of 23 types of verbal behaviours. These data were analyzed using correspondence analysis, to reduce them to a smaller number of verbal categories, in which two socio-emotional categories and three categories with task-related communication, could be distinguished. For each encounter five summary statistics corresponding to these categories were calculated.

Using analysis of variance, it was shown that the amount of socio-emotional interaction in both settings appeared to be higher than was reported in previous studies into nurse-patient communication. Compared with the home for the elderly, communication was more task-related in home care. O1998 Elsevier Science Ltd. All rights reserved.
\end{abstract}

Keywords: Nurse-patient interaction; Elderly care; Observation Study

\section{Introduction}

Communication is a central theme in nursing. Nurses depend upon their communicative skills to be able to understand and meet the needs of their patients. For elderly patients, effective communication is essential for their feelings of satisfaction, independence and wellbeing. If communication fails, patients' needs may remain unmet, their socialization process could be disturbed and compliance may decrease, which may increase the stress on nurses (Staab and Hodges, 1996).

In nurse-patient communication different communication goals have to be met. In answer to health

\footnotetext{
*Corresponding author. Tel.: 0..-31302729725; fax:
} 0..-31302729729; e-mail: w.caris(ar NIVEL. NL related problems, patients want to get information, advice and physical care, which require task-related or instrumental communication. On the other hand, patients have a need for support, recognition and understanding, which demands affective communication (Bensing, 1991; Moore and Gilbert, 1995). The latter kind of communication is especially important for the establishment of an equal and reciprocal relationship between nurse and patient in which information exchange, negotiation and decision making as regards nursing goals can take place.

Although it is widely accepted that communication is essential in nurse patient interaction, previous research has shown that interpersonal communication between nurses and elderly patients is often inadequate (Oliver and Redfern, 1991; Hollinger and Buschmann, 1993). Studies have demonstrated that most of the nurse-patient interactions seem to be superficial and task-related and 
that the amount of social interaction is limited (Nolan et al., 1995; Armstrong-Esther et al., 1994, 1989; Avis, 1994; Salmon, 1993; Kihlgren et al., 1993; Liukkonen, 1992; May, 1990). Other studies show that nurses exert power in communication (Hewison, 1995) or show a tendency to take over care and responsibility (Waters, 1994; Kenny, 1990). In this way, nursing care for the elderly is dependency creating and can give rise to iatrogenic effects, such as feelings of passivity, incompetence and depression (Miller, 1984). These considerations make nurse-elderly patient communication an important topic for research. This study focuses on communication, as an essential prerequisite for mutual goal setting and individually tailored care.

\subsection{Theoretical context}

The theoretical model of King (1981) has been the point of departure for a better grasp of the complex and broad issue of nurse patient communication. In an earlier review of the literature (Caris-Verhallen et al., 1997), we noted that communication was a vital concept in this framework. Furthermore, the King model is especially suitable for geriatric nursing, because the focus is on patient's active involvement in health care, which does not foster the growing dependency of the elderly (Kenny, 1990).

In her General Systems Framework, King discerns three dynamic interacting systems: the "personal system" (the individual), the "interpersonal system", comprising at least two interacting individuals and the "social system" of which the other two systems are part, such as families and health care settings. Nursing takes place in what King defines as the interpersonal system, to which this article will restrict itself (Fig. 1). King elaborates the nursing process using the "theory of goal attainment", in which nursing is defined as a "process of human interaction between nurse and patient whereby each perceives the other and the situation; and through communication, they set goals, explore means and agree on means to achieve these goals". Because there is some kind of goal setting in each nursing situation (King, 1981), the model can be applied in a diversity of nursing settings.

King (1981, p. 146) defines communication as the information component of interactions. The way communication takes place is determined by the goals of the communication. According to these goals different communication behaviours can be identified (King, 1981):

- affective or socio-emotional communication, which is needed to establish an collaborative rclationship with the patient;

- exchanging and interpreting information to recognize presenting conditions such as a health problem, a social problem or a human concern;
- operations related to the situation or conditions, such as decisions about goals. Mutual tuning (Bensing et al., 1995) is important for this type of behaviour, so that negotiating about goals can take place;

- motivating the patient to exert some control over the events in the situation to achieve goals.

Counselling behaviour is important within these interactions.

\subsection{Communication with elderly patients in different set- tings}

This research has been carried out in home care and in a home for the elderly. It specifically investigates whether these different care settings are related to the type of communicative behaviour employed by nurses, because the way a person communicates is influenced by the setting.

The populations of patients in these settings differ. Due to national policy in the Netherlands, by which through extension and differentiation of care facilities in the community, institutionalized care for the elderly is postponed, the residents in a home for the elderly are on average 10 years older than patients in home care (Coolen, 1993). As a result there are more female residents in a home for the elderly.

In institutional care, daily activities are more tightly scheduled than in home care. The elderly in residential care live on a ward, and experience the cultural effects, the organization and regulation of the ward, which, most of the time, imposes rigid routine on both staff and residents (Waters, 1994). In home care, patients live independently, there is no ward organization or routine to influence nurse-patient communication, although the nurse's visit can be determining for the patient's daily routine.

Institutional nursing care carries on all day, while in the community there is an explicit start and finish to the nursing encounter. Nurses in the community work more independently compared with nurses in a home for the clderly, who are a member of a team. The latter may also have a different attitude towards their patients. Since the expectation is that their patients will remain institutionalized, nurses foresee that they will deteriorate and so less effort is expended to teach them to help themselves (Dijkstra ct al., 1995; lngham and Fielding, 1985). Actually the nurses tend to take over care and responsibilities and take control over patients in the care giving process (Lancely, 1995; Hewison, 1995). In the community, nurses show more often a nursing model in which patient's self care is a central concept (Dijkstra et al., 1995). These nurses consider care as temporary and they encourage self-care (Poole and Rowat, 1994).

Another important characteristic of institutional care is a nurse-patient relation, which is strongly reciprocal 
Social system:

$\triangle$ home care

$\triangle$ home for the elderly
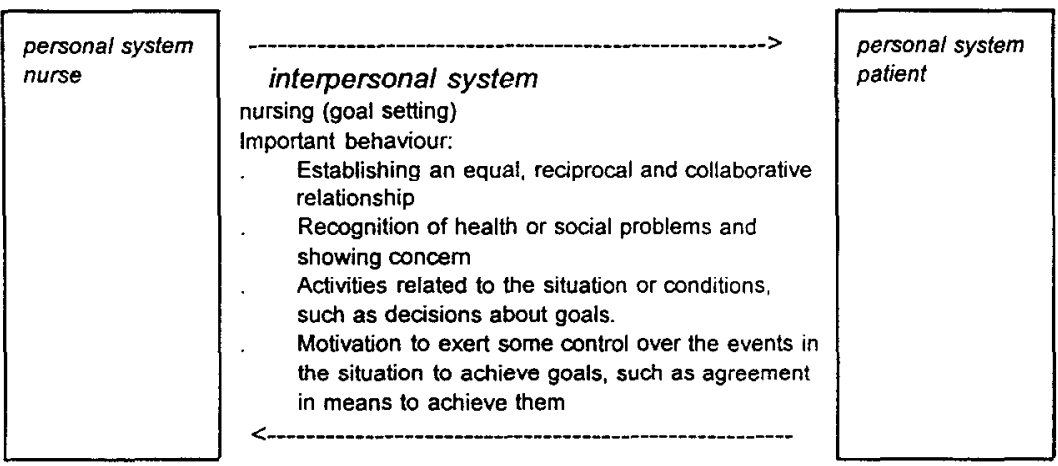

Fig. 1. Conceptual framework with dynamic interacting systems.

and familiar. Because the care is long-lasting and often intimate, the relationship between caregiver and resident mimics a family bond (Nyström and Segesten, 1996; Sumaya-Smith, 1995). In an earlier study (Caris-Verhallen et al., 1997) these relationships seemed to be less strong in home care.

\subsection{The ain of the study}

Using King's theoretical model this study has been undertaken to examine the extent to which nurses manifest the communicative ability essential for nursing. The research question addressed in this paper is: Is there a general difference in nurse-patient communication in community or in institutional care, as regards socioemotional behaviour, information exchange, mutual tuning and motivating patients to take control of their situation?

In view of the previously confirmed contrast between the different care settings, mentioned above, (De Gruyter and Schirm, 1995; Caris-Verhallen et al., 1997) it may be expected that communication in institutional care contains more behaviour directed at establishing a relationship. In particular. communication in institutional care will contain more social conversation. Communication in home care is expected to involve more negotiation about goals, mutual tuning and decision making. Moreover nurses' talk will more often concern nursing activities, medical or therapeutical topics than the communication in the elderly home. Consequently, communication in home care is likely to be more taskrelated and communication in the home for the elderly will probably have more socio-emotional aspects. As nurses in home care consider their nursing care as temporary, it is expected that they will more often motivate their patients to take control of their situation than nurses in institutional care.

\section{Methods}

\subsection{Data collection}

Video-taped data of nurse--patient interaction have been collected, mostly during morning care and sometimes during the evening. In the latter cases the type of care was comparable with morning carc. Each interaction was video-taped entirely using a manned camera, with the exception of nursing activities whereby the patient was undressed. In these cases the video camera was on the nurse, or where that was impossible only verbal communication has becn rccorded. In a pilot study (De Gruyter and Schirm, 1995), the collection and observation of video-taped interactions was shown to be a feasible method for analysing nurse-patient communication. Nurses recruited the patients for this study. A few days, prior to the data collection, nurses informed their patients about the research, and they asked patients of 55 or over' to give informed written consent to participation. Very sick patients, patients suffering from dementia and terminally ill patients were excluded from participation.

\footnotetext{
'Following the policy documents of the Dutch Government, we used a lower age-limit of 55 years in this study.
} 
In home care very few patients refused permission to participate. However, because patients were asked by their nurses some kind of selection had already taken place. In the home for the elderly residents were more hesitant about co-operating. Of the sixty residents who were asked to participate half did. Nurses did not systematically inform us about those patients who did not want to co-operate, but they reported that there was no clear difference between participant and non-participant residents.

\subsection{Nurses}

Forty seven nurses took part in this study. They all were participants in a larger project, in which training in communication skills was given and evaluated, using a pre-test, post-test design. We report about the pre-test in this article. Twenty-four nurses worked in a home care organization and provided nursing care in the community. Twenty-three nurses provided care in a home for the elderly. For each nurse, three or four encounters with patients were recorded. The two groups did not differ significantly with respect to age, gender, education and years of experience (Table 1).

\subsection{Patients}

One hundred and nine patients, agreed to participate in the study. Together they participated in 181 recorded nursing encounters. Eighty one patients lived in the community, their mean age was 77.5 years with a median of
80 (range 55-96). Most of the patients in home care received nursing care for a long period (mean 37 months).

Twenty-eight patients were residents of a home for the elderly. As expected, these patients were older than the patients in the community. Their mean age was 86.7 years (range 79-95). On average, they lived about five and a half years in the home for the elderly. Table 2 gives an overview.

These two groups of patients formed representative samples of the populations of patients in the community and in homes for the elderly, as regards age and gender (Delnoij et al., 1996; CBS, 1995).

\subsection{Observation scheme}

In order to gain more insight into nurse-patient communication the video-taped interactions were observed using Roter's Interaction Analysis System (RIAS) (Roter, 1989). This scheme, which was originally designed to code doctor-patient communication, uses verbal utterances as a unit of analysis. An utterance is defined as the smallest distinguishable speech segment to which a coder can assign a classification. This may be a word, a clause or a complete sentence. All utterances are assigned to mutual exclusive categories. RIAS provides the option of coding directly from a video tape. The system is widely used and has been shown to be reliable (Van Dulmen et al., 1996; Van den Brink, 1996; De Gruyter and Schirm 1995; Bensing, 1991) and was relatively favourable judged in a comparative study (Inui et al., 1982). RIAS seemed suitable for our study, because it pays attention to socio-

Table 1

Distribution of age, sex, education and amount of years of nursing experience of nurses participating in the study $n=47$

\begin{tabular}{|c|c|c|c|}
\hline & $\begin{array}{l}\text { Nurses in the } \\
\text { community } \\
n=24\end{array}$ & $\begin{array}{l}\text { Nurses in a home } \\
\text { for the elderly } \\
n=23\end{array}$ & $\begin{array}{l}\text { Total participating } \\
\text { nurses } \\
n=47\end{array}$ \\
\hline Women ${ }^{b}$ & 24 & 21 & 45 \\
\hline Men & 0 & 2 & 2 \\
\hline Mean age & 37.4 & 40.9 & 39.1 \\
\hline (S.D.) & $(9.3)$ & $(8.7)$ & $(9.1)$ \\
\hline \multicolumn{4}{|l|}{ Education ${ }^{\mathrm{b}}$} \\
\hline Registered nurse & 11 & 8 & 19 \\
\hline Nursing auxiliary & 13 & 14 & 27 \\
\hline Nursing assistant & & 1 & 1 \\
\hline \multicolumn{4}{|c|}{ Years of experience as a nurse ${ }^{a}$} \\
\hline Mean & 16.5 & 15.9 & 16.2 \\
\hline (S.D.) & $(8.8)$ & $(7.2)$ & $(8.0)$ \\
\hline
\end{tabular}

${ }^{a}$ Differences in age and amount of experience were tested by means of $t$-tests.

${ }^{\mathrm{b}}$ Differences in gender and education level were tested by means of a chi-square tests. 
Table 2

Distribution of age, sex and duration of receiving nursing care of patients, who took part in the study $n=109$

\begin{tabular}{|c|c|c|c|}
\hline & $\begin{array}{l}\text { Patients in the } \\
\text { community } \\
n=81\end{array}$ & $\begin{array}{l}\text { Patients in home } \\
\text { for the elderly } \\
n=28\end{array}$ & $\begin{array}{l}\text { Total participating } \\
\text { patients } \\
n=109\end{array}$ \\
\hline Women & 53 & 25 & 78 \\
\hline Men & 28 & 3 & 31 \\
\hline $\begin{array}{l}\text { Mean age } \\
\text { (S.D.) }\end{array}$ & $\begin{array}{l}77.5 \\
(8.7)\end{array}$ & $\begin{array}{l}86.7 \\
(4.4)\end{array}$ & $\begin{array}{l}79.9 \\
(8.8)\end{array}$ \\
\hline $\begin{array}{l}\text { Mean duration of received nursing } \\
\text { care in months } \\
\text { (S.D.) }\end{array}$ & $\begin{array}{l}37 \\
(43.6)\end{array}$ & $\begin{array}{c}70 \\
(77.2)\end{array}$ & $\begin{array}{l}45 \\
(55.8)\end{array}$ \\
\hline
\end{tabular}

emotional and instrumental communication which are both important for goal setting; however, it had to be adapted for nurse-patient communication. A pilot study was carried out for that purpose (De Gruyter and Schirm, 1995). The original 34 categories were reduced to 24 verbal categories. Medical and therapeutic items were conflated to "nursing" items, because these topics seemed to be intertwined in the nursing situation. The same happened with items relating to lifestyle and feelings. In the adapted version, the following groups of variables can be distinguished as indicators for important communication behaviours, according to King (see theoretical context):

- communication that is directed at establishing a relationship, which will be referred to as socioemotional communication. It includes social conversation, empathic behaviour, showing concern, warmth and interest;

- communication directed at mutual tuning and seeking agreement, such as asking for understanding and clarification, asking for an opinion. These behaviours are considered to be important in making decisions about goals;

- communication directed at recognizing problems and providing information in order to set goals for their solution. This includes information exchange on nursing and therapeutical items or lifestyle and emotional topics;

- counselling behaviour to teach the patient to take control over events, to achieve goals.

Because communication during nursing encounters is characterized by the kind of procedures that are carried oul, nursing care was also coded. Using Kerkstra and Vorst-Thijssen (1991), (who categorized three types of nursing care) as a point of departure, we discerned: encounters dominated by hygienic care, encounters principally involving technical nursing procedures and encounters which were dominated by psycho-social care. Table 3 gives an overview of the observation categories.

\subsection{Reliability of the observations}

The video records were systematically observed with RIAS by two observers using the CAMERA computer system (Iec ProGAMM 1 , 1994), which is especially designed for coding behavioural interactions from video recordings. The reliability of the observation frequencies proved to be high, with inter-observer correlations varying between 0.69 and 1.00 (Pearson's $r$ ) for the RIAS catcgories and between 0.80 and 1.00 (Pearson's $r$ ) for nursing activities (Table 3 , column 2 ).

Preliminary observations, with observation periods of 5 and $10 \mathrm{~min}$, were carried out on 48 encounters based on findings of Henbest and Fehrsen (1992), who noted that scoring only a part of the consultation could be as reliable as scoring an entire consultation. As $10 \mathrm{~min}$ observation periods proved to be the most reliable (correlations between 0.65 and 0.98 , Table 3 column 3 ), observation time was standardized and the first $10 \mathrm{~min}$ were observed of each nursing encounter.

\subsection{Analysis}

Observations using the CAMERA system provide a detailed description of 181 nursing encounters, in which each encounter is characterized by counts of 23 verbal RIAS categories (the category "non-categorizable utterances" was excluded from analysis). Actually the dataset could be described as a table with 181 rows (encounters) and 23 columns with counts of RIAS categories. Each row presents a specific frequency pattern derived from the number of times each of the RIAS categories is scored. As an example, the 23 counts for one of the encounters are $45,4,0,1,1,4,0,29,3,2,0,10,0,9,0,16,0,1,0,26,0$, 
Table 3

Overview of reliability coefficients

\begin{tabular}{|c|c|c|c|}
\hline $\begin{array}{l}\text { Variables } \\
\text { (abbreviations) }\end{array}$ & & $\begin{array}{l}\text { Reliability coefficients } \\
\text { Interrater reliability } \\
\text { (Pearson's } r \text { ) } \\
\text { two observers for RIAS } \\
\text { categories and nursing } \\
\text { activities }\end{array}$ & $\begin{array}{l}\text { (Pearson's } r \text { ) } \\
\text { comparing the first ten- } \\
\text { minute scores with } \\
\text { scores of the entire } \\
\text { nursing encounter }\end{array}$ \\
\hline \multicolumn{4}{|l|}{ Verbal behaviour } \\
\hline Personal remarks/social conversation & (pers) & 0.79 & $0.92^{* *}$ \\
\hline Jokes laughter & (joke) & $0.97^{*}$ & $0.94^{* *}$ \\
\hline Compliments/approval & $(\mathrm{cmpl})$ & 0.69 & $0.94^{* *}$ \\
\hline Shows concern/worry & (conc) & 0.87 & $0.97^{* *}$ \\
\hline Reassurance/encouragement/optimism & (reas) & $0.99^{* *}$ & $0.97^{* *}$ \\
\hline Empathy/legitimize & (empa) & 0.96 & $0.95^{* *}$ \\
\hline Shows partnership and support & (part) & $1.00^{* * *}$ & $0.94^{* *}$ \\
\hline Shows agreement/understanding & (agre) & 0.88 & $0.95^{* *}$ \\
\hline Paraphrase/interpretation & (para) & 0.72 & $0.94^{* *}$ \\
\hline Asks for reassurances & (area) & $1.00^{* *}$ & $0.96^{* *}$ \\
\hline Disagreement/misunderstanding/criticism & (disa) & $1.00^{* *}$ & $0.72 * *$ \\
\hline Orientations/instructions & (orie) & $0.98^{*}$ & $0.92 * *$ \\
\hline Requests for clarification & (bids) & $1.00^{* *}$ & $0.78^{* *}$ \\
\hline Asks for understanding & (aund) & 0.95 & $0.93^{* *}$ \\
\hline Asks for an opinion & (aopi) & $1.00^{* *}$ & $0.98 * *$ \\
\hline Closed questions: nursing/therapeutic items & (gnur) & $0.98^{*}$ & $0.91^{* *}$ \\
\hline Open questions: nursing/therapeutic items & (onur) & $1.00^{* *}$ & $0.96^{* *}$ \\
\hline Information about nursing/therapeutic items & (inur) & 0.95 & $0.92^{* *}$ \\
\hline Closed questions : lifestyle/feelings & (glif) & $0.98^{*}$ & $0.91 * *$ \\
\hline Open questions : lifestyle/feelings & (olif) & $1.00^{* *}$ & $0.90^{* *}$ \\
\hline Information about lifestyle/feelings & (ilif) & $0.98^{*}$ & $0.90^{* *}$ \\
\hline Counsels nursing/therapeutic behaviour & (cnur) & 0.81 & $0.65^{*}$ \\
\hline Counsels lifestyle behaviour and feelings & (clif) & $1.00^{* *}$ & $0.92 * *$ \\
\hline Not categorizable utterances & (othe) & $0.99^{* *}$ & $0.92^{* *}$ \\
\hline \multicolumn{4}{|l|}{ Nursing activities } \\
\hline Hygienic care & & $1.00^{* *}$ & \\
\hline Technical nursing procedures & & $0.80^{*}$ & \\
\hline Psycho-social care & & $0.90^{*}$ & \\
\hline
\end{tabular}

$* P<0.05,{ }^{* *} P<0.01$.

4,0 . The data analysis was intended to provide a more detailed picture of nurses' communicative behaviour.

Firstly, we determined whether a clustering was feasible in RIAS-variables by means of Correspondence Analysis (CA): a method used to analyze data as described above.

The aim of CA in the analysis presented in this paper is similar to the aim one would have with Factor Analysis (FA), namely clustering the RIAS-variables (columns of the table) into a lower number of grouped activities, but because of methodological reasons FA was not suitable for this dataset (Appendix).
CA was applied using ANACOR (SPSS module). ANACOR provides two types of plots: plots on which row profiles are plotted and plots with plotted column profiles (see Figs 2 and 3). The interpretation of these plots is fairly simple. On plots of column profiles, points that are close together are more alike than points that are far apart. This allows clustering of the RIAS categories, meaning that there is a similarity in RIAS-categories that were plotted near to each other, in the sense that they are used often in the same kind of encounters. RIAScategories plotted far apart differ from each other, meaning that they are used often in different encounters. 
With the other type of plots, ANACOR allows the clustering of different encounters. These plots can be interpreted in a comparable way, i.e. encounters that are close together refer to encounters with a similarity in patterns of RIAS categories, while encounters that are far apart have a very different pattern. Combining the two plots (cncounters and RI $\Lambda$ S-categories) enables to see whether specific encounters are characterized by special communication patterns. On the basis of such combinations it is possible, for instance, to show that communication in institutional care is different from communication in home care. The latter way of interpreting CA will not be applied in this study, because the only aim we had here was clustering RIAS variables.

After the RIAS categories had been clustered the communication in the two different care settings was analyzed in more detail. For cach eluster representing a type of verbal behaviour summary statistics were calculated. Than an analysis of variance was used. In addition to the (independent) variable "setting" the variable "type of nursing care" was involved, indicating whether hygienic, technical or psycho-social care was provided. Wc investigated whether setting and type of nursing care affected nurse-patient communication.

\section{Results}

\subsection{Clustering the RIAS categories using correspondence analysis}

Our adapted version of RIAS consists of 23 verbal communication categories.

Using CA we investigated whether these 23 categories could be reduced to meaningful clusters. The underlying assumption of RIAS is that in provider-patient communication two types of behaviours can be discerned, namely task-focused/instrumental and socio-emotional/affective exchange. Both types of behaviour are recognized as important in health communication (Roter, 1989). Using a preliminary CA, this classification in two main clusters was confirmed and it could be concluded that socio-emotional variables and instrumental variables were two different dimensions which are not strongly related. The socio-emotional variables dominated dimension one, and the lask-related categories were mainly represented by dimension 2 .

To find a clustering within these two main groups we carried out $\mathrm{CA}$ on affective and instrumental variables separately.

An analysis of the 181 encounters by 11 socioemotional RIAS categories showed at first five eigenvalues (with proportions of explained total distance) 0.32 $(41 \%), 0.08(11 \%), 0.07(9 \%), 0.07(9 \%)$ and $0.06(7 \%)$. As the second eigenvalue was not clearly separated from the later ones, we decided to use the first dimension. (compare the screen test for factor analysis).

Figure 2a shows personal remarks and joke/laughs on the right versus the other socio-emotional categories on the left. Figure $2 \mathrm{~b}$ shows the 181 encounters, where each encounter is labelled by either home care or institutional care. Figure $2 b$ is related to Fig. $2 a$ as follows: in the encounters on the right personal remarks take up a relatively large part of the communication, whereas in encounters on the left, communication comprises a relatively large degree: giving and asking for reassurance. empathy, showing concern, paraphrasing, agreement, disagreement, giving compliments and approval. Because we find more home care encounters on the right we conclude that in the home for the elderly especially, the encounters are characterized by personal "chat" and jokes (Fig. 2b).

As a result we distinguish two socio-emotional clusters in this study. The cluster on the right can be considered as social behaviour, which provides information about the degree to which the nurse uses social conversation that has no particular function in nursing activities such as personal statements, jokes and small talk. The cluster on the left can be considered as an affective cluster,which provides information about the extent the nurse shows verbal attentiveness (Bensing 1991), concern and empathy with emotional aspects of the patient.

In further analysis, we will cluster the 11 RIAS-categories into these two groups by adding up the counts in each of the encounters. ${ }^{2}$

The CA relating to the 12 instrumental RIAS categories at first shows five eigenvalues of $0.29(35 \%), 0.14$ $(17 \%), 0.07(9 \%), 0.07(8 \%)$ and $0.06(0.07)$. Because the third eigenvalue was not clearly separated from the later ones, we decided to use the first and the second dimensions.

The plot of column points shows a clustering of three groups of variables. Bottom right of Fig. $3 a$ there is a cluster with utterances that indicate guidance and direction such as orienting and instructing, requests for clarification, asking for understanding and asking for opinion. We call this cluster "communication that structures communication". Top right a second cluster is found, that contains all items with respect to nursing,

\footnotetext{
2 Since "jokes" is in between two dusters, we also investigated what the effect would have been on the other analyses, reported in this paper, when jokes would have been included in the cluster "affective communication". The effect is minimal, mainly because the frequency of "jokes" is low. Since in other research (Bensing, 1991; Van Dulmen et al., 1996) jokes were included in a cluster 'social behaviour' we have decided to include it in this cluster.
} 
pers= personal remarks

joke= jokes/laughs

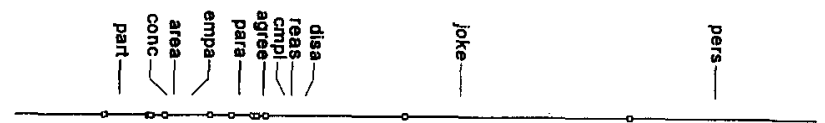

$\mathrm{cmpl}=$ approval/compliments

cons= showing concern/worly

reas $=$ reassurance

empa $=$ empathy/legitimize

part= partnership

agre $=$ agreement

para $=$ paraphrase

disa $=$ disagree

area $=$ asks for reassurance
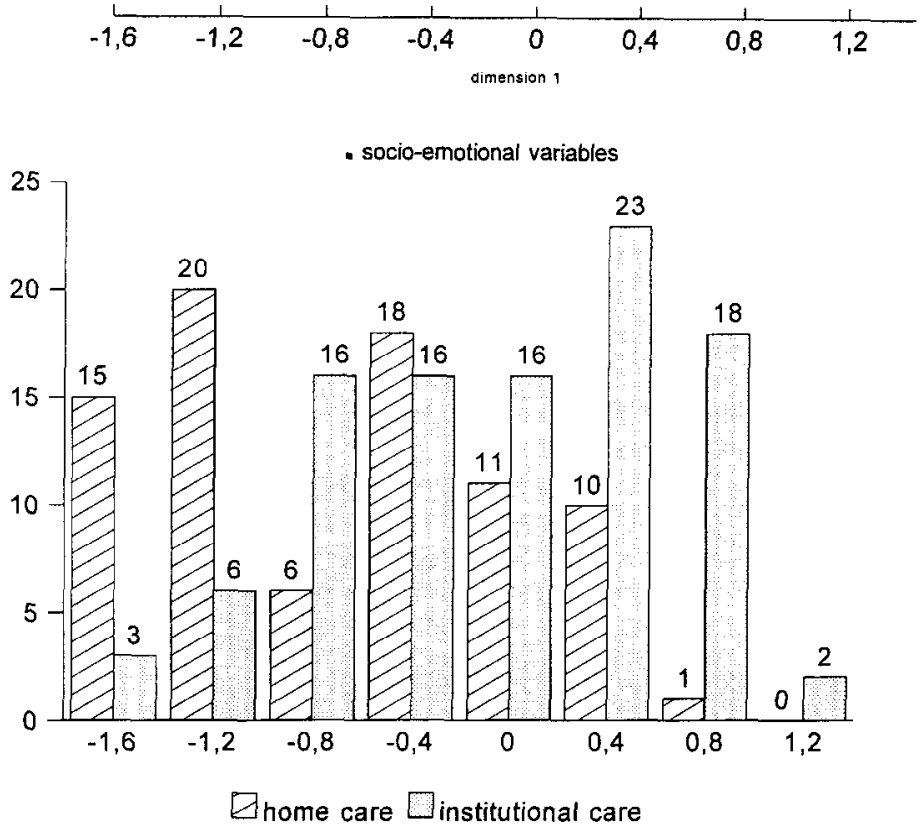

Fig. 2. Profiles of encounters $(n=181)$ involving affective RIAS-categories depicted on one dimension.

medical or therapeutical topics. ${ }^{3}$ We call this cluster "communication nursing and medical topics". On the left a third cluster contains all items with respect to lifestyle and feelings. This cluster is called "communication lifestyle and emotional topics".

When we compare Fig. 3a with the plot on which the different encounters are depicted (Fig. 3b), it can be concluded that there are nursing encounters which are dominated by items relating to lifestyle and feclings and other encounters which are dominated by communication relating to nursing, medical and therapeutic topics. These latter topics are more often represented in home care.

In conclusion, as a result of the $\mathrm{CA}$, two socio-

\footnotetext{
${ }^{3}$ Including "gnur" in this cluster is based on both analysis of Fig. $3 \mathrm{a}$ and content analysis.
}

emotional clusters are formed: "social behaviour" and "affective behaviour". Three instrumental clusters are formed: "variables that structure the communication", "information exchange concerning nursing and medical topics" and "information exchange involving lifestyle and emotional topics".

\subsection{Differences in nurses verbal behaviour in two different care settings}

From Fig. 2b we concluded that nurse-patient communication in the home for the elderly includes more social behaviour than in home care. Apart from that, according to Fig. $3 b$, it seems that in home care the nursing encounters are more often about nursing or medical topics, while communication in institutional care involves more lifestyle and emotional topics.

To analyze the communication of nurses in the two 

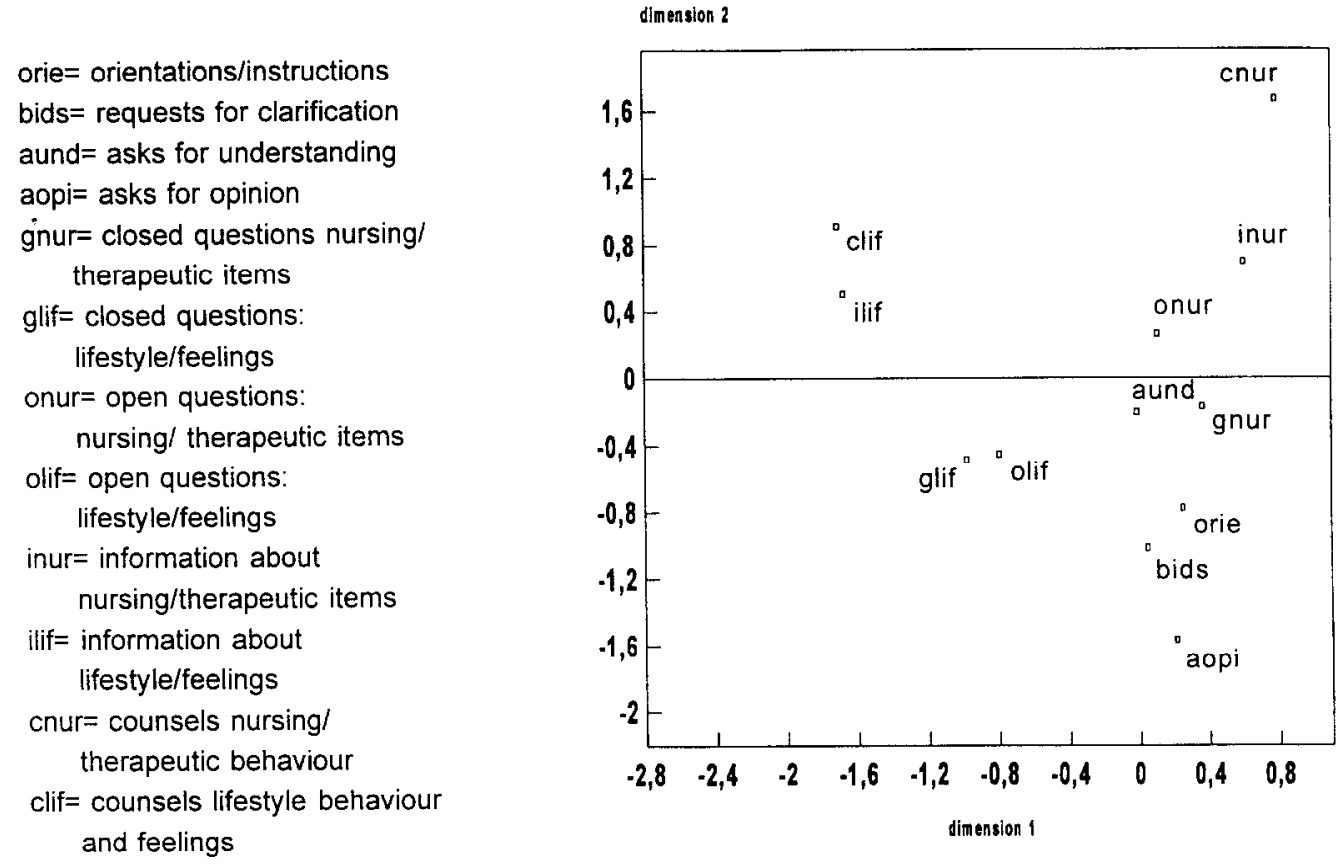

- Instrumental variables

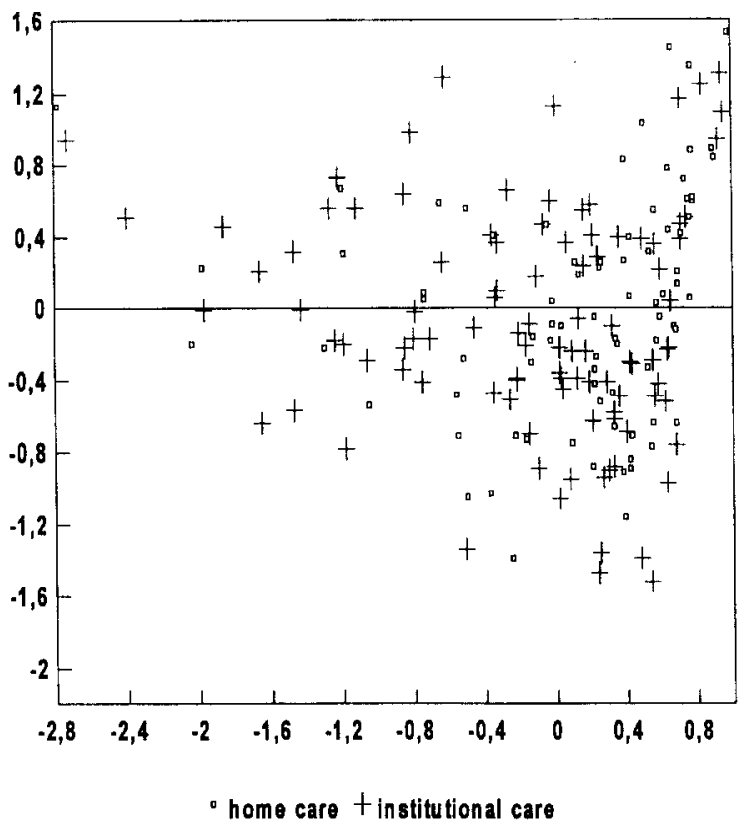

Fig. 3. (a) Profiles of 12 instrumental RIAS-categories depicted in a two dimensional plot. (b) Profiles of encounters $(n=181)$ involving instrumental RIAS-categories depicted in a two dimensional plot.

different care settings more specifically, a two way analysis of variance was carried out on five clusters of verbal behaviour as observed with RIAS and clustered with CA.

The independent variables were "setting" and "type of nursing care". The latter was included because it was plausible to think that nurse-patient communication var- ies during different kinds of nursing activities. The dependent variables are defined as the proportion of total amount of utterances nurses spent within one of the five types of verbal behaviour. The results of the ANOVA are shown in Table 4.

In general it seems that the communication between 
Table 4

Results two-way analysis of variance: Independent variables: setting, type of encounter. Dependent variables: proportion of total amount of utterances nurses spent within one of the five types verbal behaviour

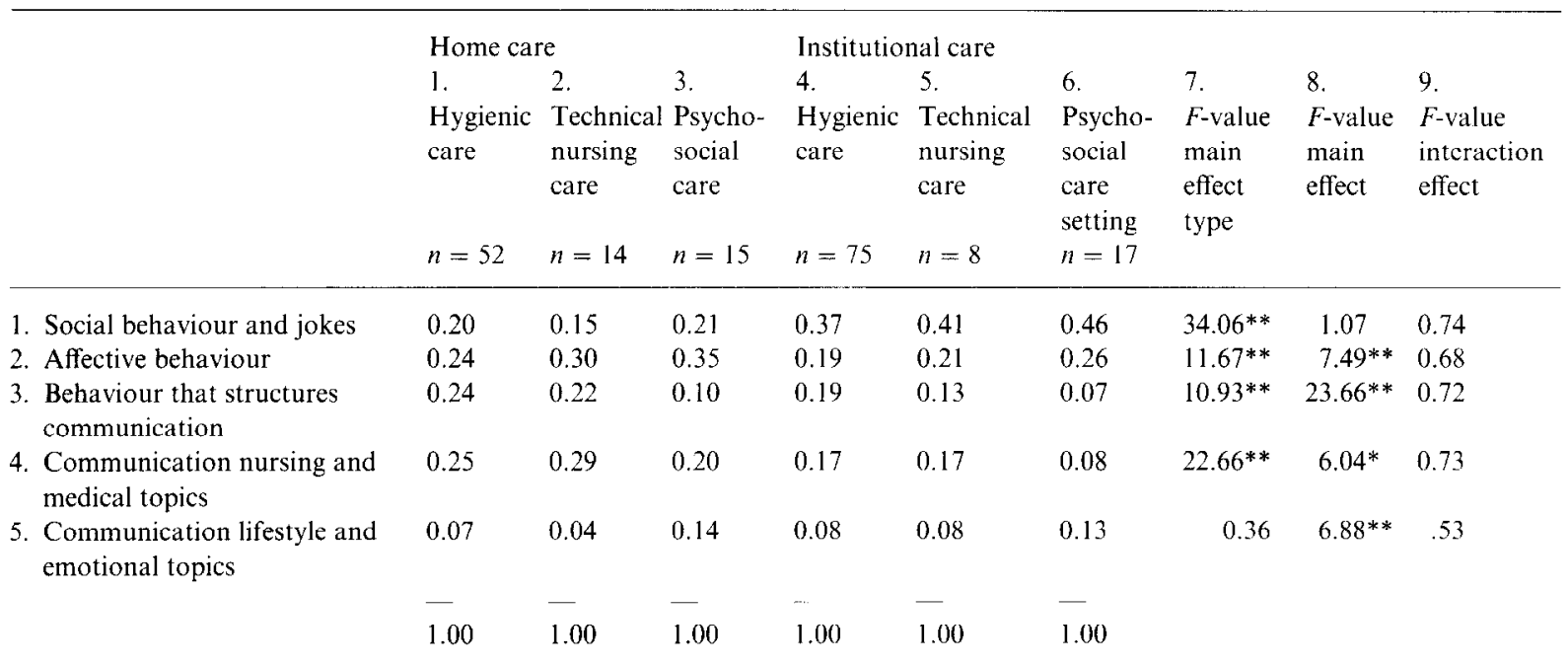

** Significance level of $F \leqslant 0.001$.

* Significance level of $F \leqslant 0.01$.

nurses and elderly patients is characterized by socioemotional conversation to a large extent. Between $44 \%$ and $72 \%$ (summing up the proportional frequencies of the first two rows) of the verbal utterances in home care and institutional care are social or affective in nature. As expected, in institutional care, there is much more social behaviour (row 1 in column 4-6) than in home care (column 1-3). The other affective categories (row 2) were relatively more often shown in home care than in the home for the elderly. It seems that although communication in institutional care contains more socioemotional aspects, nurses in home care show more variety in the way they display socio-emotional behaviour. In a more detailed analysis (not in Table 4) nurses in home care show significantly more concern, agreement and paraphrases.

As regards social behaviour (row 1) there is no effect from the type of nursing care that is provided. On the contrary, affective behaviour (row 2) is influenced by the type of care that is given. Still, the effect of setting is stronger than the effect from the type of nursing care, in the sense that nurses in home care show more affective behaviour (row 2).

In home care nurses more often show verbal behaviour that structures the communication (row 3), like "asking for an opinion", "asking for understanding" and statements that guide the patient through the nursing encounter, like "orienting and instructional remarks". There is an even stronger effect from the different nursing activities, in the sense that communication in hygienic and technical nursing care involves more statements that structure the encounter than communication in psychosocial care. This is not too surprising a finding, because this cluster includes utterances that indicate direction and instructing, which are quite common in hygienic and technical care ("turn around please" "here is your dress').

The information exchange in home care is more often directed at topics relating the nursing activity and medical or therapeutic items (row 4), than in institutional care. This is especially the case in encounters that are dominated by technical nursing. It is not surprising, because this kind of information exchange is more or less inherent in technical nursing procedures. The effect of the setting is more strongly present than the effect of type of nursing care. The information exchange involving lifestyle and emotions (row 5 ) is effected more by type of care than by setting. It is not surprising that talking about lifestyle and emotional topics coincides with psycho-social care because these are part and parcel of it. A more detailed analysis (not inTable 4 ) revealed that home care nurses display more counselling behaviour, especially counselling in nursing, medical and therapeutical topics, than nurses in the home for the elderly. The latter confirms expectations about counselling behaviour.

For none of the communication clusters was there an interaction effect with the setting and type of care, meaning that a particular combination of the independent variables (setting and type of care) does not reveal unexpected communication strategies. In other words, the difference between settings in communication is the same in the three different types of care. 


\section{Discussion}

In this study we investigated the extent to which nurses show behaviour that is essential for nursing and goal setting in their communication with elderly patients. Special attention was paid at two different care settings.

Results demonstrated that nurses in the home for the elderly showed more social behaviour than nurses in home care. Even when different nursing activities were involved in the analysis, nurses in institutional care showed relatively more social behaviour than nurses in the community. These results are in line with our expectations.

Affective behaviour through which support, concern and empathy was expressed, was more often shown by nurses in home care than by nurses in institutional care. It was also anticipated that nurses in home care would talk more frequently about nursing and therapeutical topics than nurses in institutional care. This was found to be true. On the other hand, there was no difference between the two settings in communication about lifestyle and emotional topics. There was only a slight difference in counselling behaviour of nurses in institutional and home care. Nurses in home care more often showed counselling behaviour that was related to the nursing and medical condition. As regards lifestyle and emotional topics, there was no difference in counselling behaviour. As the nurses home care and the home for the elderly were comparable in terms of age, education and years of experience, this difference can be attributed to the different care settings.

One remarkable finding in this study was the amount of socio-emotional communication the nurses showed. About half of the verbal utterances used in this study were directed at the establishment of a relationship between nurse and patient and concerned personal talk, jokes and other affective behaviour. This result was inconsistent with findings from previous studies in nursing the elderly. which showed most of the nurse-patient interactions to be task-related and that the amount of social interaction was limited (May, 1990; Liukkonen, 1992; Kihigren et al., 1993; Salmon, 1993; ArmstrongEsther et al., 1993, 1989; Nolan et al., 1995). These results could not be attributed to specific patient samples. In terms of age and gender, the two groups of patients under study were comparable to the populations of patients in the community and elderly homes. This result may perhaps be attributed to the fact that two thirds of the patients had received nursing care for a year or longer. Possibly therefore communication patterns reflect a daily routine in nursing by which there is less need for taskrelated communication like explication and information exchange. Because the results are based on two samples in specialized settings the results must be interpreted with caution and can not be generalized to other health care settings.

Some methodological issues are worth mentioning. In an earlier study of the literature (Caris-Verhallen et al., 1996) we stated that theory based studies of the nursepatient communication were scarce. Consequently there were hardly any observation instruments, which were suitable for nurse-patient communication and appropriate to test a theoretical nursing model. In this explorative study we took the model of King (1981) as point of departure, because communication is a central theme in this framework and because it was judged particularly suitable for nursing elderly people (Kenny, 1990). We made an effort to adapt RIAS, which was originally designed to code doctor-patient communication, for our study. This adapted version of RIAS has proven to be suitable for analysing nurse-patient communication. RIAS was ablc to discern different types of verbal behaviour which were considered to be essential in nursing. With the application of CA, five different clusters of verbal behaviour could be distinguished. These clusters corresponded partly with the important nursing behaviours, which King (1981) discerned, such as socioemotional communication, which is needed to establish a relationship with the patient; exchanging and. interpreting information to recognize presenting conditions. and mutual tuning. Unfortunately using CA, counselling behaviour was not noted as a separate cluster. This kind of behaviour is directed at motivating patients to take control of their situation. Apparently in communicating with elderly patients this kind of behaviour is inherent in questioning and sharing information. Despite this shortcoming, the RIAS appeared to be sensitive to communication differences in home care and institutional care and to different communication patterns during different types of nursing encounters.

In this study it was shown that video-taping is a feasible method in nursing research. However this method has some limitations. Firstly, the nurses were not a random sample, but nurses who were going to receive training in communication skills were participants in the study. Because patients were recruited by the nurses themselves in the patient group as well some selectivity could have appeared. This could provide a limited bias in the data and accordingly no conclusions can be drawn about nurse-elderly patient communication in general. Secondly, there is some concern as to whether nurses may have been subject of performance bias (Levinson and Roter, 1993), meaning that nurses, being aware of being video-taped, possibly behaved differently from normal. We think that this type of bias was limited because the study was part of a larger project in which video feedback was used as a training method, so the nurses were more or less used to being recorded. Moreover the video taping continued for half-a-day and it is described in literature that persons concerned tend to resurne their natural behaviour in a fairly short time (Verhaak, 1988; Schepers, 1991). Apart from that, most of the nurses and patients reported afterwards in a questionnaire that the videotaped encounter was comparable to the normal situation. 
Although a major benefit of video tapes is that research in both verbal and non-verbal behaviour is possible, this study was only directed at verbal communication. As socio-emotional communication in particular is transferred in a non verbal way, analysing non vocal behaviour would be an interesting matter.

In conclusion, the results of this study show that nurses both in the home for the elderly and in the community more often used socio-emotional communication than was reported in previous studies. Socio-emotional communication is frequently recommended in nursing care for the elderly. Because the elderly have a diminishing social network they may be dependent on the nurse-patient relationship for their social contacts. In this way social-emotional communication in the nurse-patient relationship may contribute to a better quality of life of patients

To understand more of the nature of nurse-patient communication, in future research more emphasis should given to non-verbal communication. To gain insight into the effect of communication patient outcomes should be taken into account.

\section{Acknowledgements}

This research project is financed by the Dutch Ministry of Health, Welfare \& Sports, Department for Policy on the Elderly.

\section{Appendix}

Observational data collected with the RIAS have the following form. In this study there are 23 verbal activities, and for each encounter the number of times of each of these activities is displayed is denoted. This information is then collected in data matrix of 181 encounters in the rows and 23 activities in the columns. In the cells of this matrix the number of times is found that during a specific encounter a specific activity is displayed.

In the statistical literature data like these are called "compositional data". The reason is that the counts of each row of the matrix describe the composition of the encounter. For statistical analysis compositional data have the property that they are not well suited for correlational techniques, such as principal component analysis or factor analysis. The reason is that for each row the total number of the count is fixed, and therefore the counts are not free to vary. More specifically: when one count is higher, there have to be other counts that are smaller. For this reason it can be proved that, if a correlation matrix would be calculated between the columns of the, then there would be at least one negative correlation in each row of the correlation matrix. This makes it difficult to use the zero-correlation as a point of ref- erence to judge dependence from independence. For more details, see Aitchison (1986).

Therefore other tools for analysis are called for. We use correspondence analysis (CA; Greenacre, 1984; see also Van der Heijden and Van den Brakel, 1993). The aim of CA in the analysis presented in this paper is similar to the aim one would have with factor analysis, namely we used it to cluster the columns of the matrix (verbal activities) into a number of grouped activities. CA represents large and complicated data matrices by graphical displays that are easy to interpret and that can be used for clustering the rows or the columns of the matrix. CA makes use of the specific properties of the observational data. We denote the count for encounter (row) and activity $j$ as $n_{i j}$, We can rescale these counts to observed proportions by dividing $n_{i j}$, by the row total $n_{i+}$.

$p_{j \mid i}=n_{j i} / n_{i+}$

where $n_{i+}+\Sigma_{j} n_{i j}$. Here $P_{j i}$ is the proportion of times of activity $j$ is used in encounter $i$. CA aims to represent the observed data matrix graphically in a low dimensional space. We will discuss CA without many technical details here, but we refer for such details to Greenacre (1984) and Van der Heijden (1987)

Starting point is the matrix with conditional proportions $p_{j i}$, where $i$ indexes the row elements and $j$ the verbal activities. Each of the 181 encounters has proportions for 23 RIAS activities adding up to 1 . So called chi-squared distances $\delta_{i j}$ between the encounter $i$ and $i^{\prime}$ of this matrix can be calculated as

$\delta_{i i}^{2}=\Sigma_{j}\left(1 / p_{+j}\right)\left(p_{j i}-p_{j \mid i^{2}}\right)^{2}$

where $p_{+j}=n_{+j} / n_{++}, n_{+j}=\Sigma_{i} n_{i j}, n_{++}=\Sigma_{i} \Sigma_{j} n_{i j}$. This shows that the chi-squared distance $\delta_{i j}$, between encounter $i$ and $i^{\prime}$ will be small when the conditional proportions $p_{j i}$, and $p_{j i}$ are very similar, and the chi-squared distance $\delta_{i j}$, will be large when there are activities $j$ for which $p_{j i}$, is very different from $p_{j i r}$. The term $\left(1 / p_{+j}\right)$ is used to downplay the influence from the activities that are performed more often. So if two encounters 'spend' their time in a similar way, their distance is small, and if two encounters spend their time in very different ways, their distance is large. By CA a graphical representation is obtained. This representation has the property that Euclidian distances between the points in the representation approximate the chi-squarcd distances as well as possible. In principle for our matrix of 181 encounters by 23 RIAS categories, 22 dimensions are needed to display the data perfectly. However comparable to the principle component analysis, CA provides a low dimensional space that reflects the distances between the points in fulldimensional space as good as possible. The sum of all eigenvalues equals the total of the squared distances to the origin that is displayed in the full dimensional space. Therefore the importance of a specific dimension can be 
assessed by dividing the eigenvalue of this dimension by the sum of all eigenvalues. A choice for a specific number of dimensions is done by studying the decline of eigenvalues: if an eigenvalue is not well separated from the remaining eigenvalues then the dimension is not studied any more (compare the use of a screen test in factor analysis). Many other details can be given here, but we refer for these to the references above and below.

It is also possible to use a similar procedure to make a representation for the column points, using a matrix with conditional proportions $p_{j i}$ to calculate chi-squared distances $\delta_{i j}$ between columns $j$ and $j^{\prime}$.

$\delta_{j}^{2}=\Sigma_{i}\left(1 / p_{i-}\right)\left(p_{i \mid i}-p_{j \mid i}\right)^{2}$

where $p_{i+}=n_{i+} / n_{++}$. Similar to the rows, a representation can be made for the columns.

The representation for the rows and the representation for the columns are closely related, in fact using one the other can be derived from it (see Greenacre, 1984). The way to interpret the relation is that rows and column depart in the same way from the origin [i.e. point $(0,0)$ if $p_{j \mathrm{i}}>p_{i+}$. (and then also $\left.p_{j \mid i}>p_{+i}\right)$ ].

Correspondence analysis is commercially available in statistical software packages like SPSS, SAS and BMDP.

\section{References}

Aitchison, J., 1986. The statistical Analysis of Compositional Data. Chapman and Hall, London.

Armstrong-Esther, C.A., Browne, K.D., McAfee, J.G., 1994. Elderly patients: still clean and sitting quietly. J. Adv. Nurs. 19. 264-271.

Armstrong-Esther, C.A., Sandilands, M.L., Miller D., 1989. Attitudes and behaviours of nurses towards the elderly in an acute caresetting. J. Adv. Nurs. 14, 34-41.

Avis, M., 1994 Choice cuts: an exploratory study of patients" views about participation in decision-making in a day surgery unit. Int. J. Nurs. Stud. 31, 289-298.

Bensing, J.M., 1991. Doctor-patient communication and the quality of care. NIVEL, Utrecht.

Bensing, J.M., Kerssens, J.J., Pasch, M. van der, 1995. Patientdirected gaze as a tool for discovering and handling psychosocial problems in general practice. J. Non-verbal Behav. 19 , 223-242.

Brink-Muinen, A. van den, 1996. Gender, health and health care in general practice: A comparison between women's health care and regular health care. NIVEL, Utrecht.

Caris-Verhallen, W.M.C.M., Kerkstra, A., Bensing, J.M., 1997. The role of communication in nursing care for the elderly: a review of the literature. J. Adv. Nurs. 25, 915-933.

Caris-Verhallen. W.M.C.M., De Gruijter, Kerkstra, A., 1997. De kwaliteit van de communicatie tussen verplegenden en oudere cliënten. NIVEL, Utrecht.

CBS, 1995. Vademecum of health Statistics of the Netherlands 1995. CBS, Voorburg/Heerien.

Coolen, J., 1993. Changing care for the elderly in the Netherlands. Van Gorcum, Assen/Maastricht.
Delnoij, D.M.J., Schuller, R., Heugten, C.M. van, Kwartel, A.J.J. van der, Smit, R.L.C., Van der Meulen, L.J.R., 1996. Brancherapport curatieve somatische zorg. NIVEL/NZI, Utrecht.

Dijkstra, G.J., Groothoff, J.W., Dassen, T., 1995. Vergelijking van lichameiijke zorgbehoefte van ouderenin drie typen instellingen. T.S.G. 73, 135-140.

Dulmen, A.M., Verhaak, P.F.M., Bilo, H.J.G., 1997. Shifts in doctor-patient communication during a series of outpatient consultations in non-insulin-dependent diabetes mellitus. Patient Educ. Couns. 30(3), 227-237.

Greenacre, M.J., 1984. Theory and applications of Correspondence Analysis. Academic Press, New York.

Gruyter, I. de., Schirm. M., 1995. Communicatie met oudere patiënten: Doctoraalscriptie. ASW, Universiteit Utrecht. Utrceht.

Henbest, R.J., Fehrsen, G.S., 1992. Patient-centredness: Is it applicable outside the West? Its measurement and effect on outcomes. Family Practice 9, 311-317.

Heijden, P.G.M. van der, Brakel, J. van den, 1993. Three data reduction methods for the analysis of time budgets. In: ISTAT: time use methodology: towards consensus. ISTAT, Roma.

Hewison, A., 1995. Nurses" power in interactions with patients. J. Adv. Nurs. 21, 75-82.

Hollinger, L.M., Buschman, M.B., 1993. Factors influencing the perception of touch by elderly nursing home residents and their health caregivers. Int. J. Nurs. Stud. 30, 445-461.

Iec ProGAMMA, 1994. User manual CAMERA: a system for collecting and correcting behavioral data. Iec ProGAMMA, Groningen

Ingham, R., Fielding, P.. 1985. A review of the nursing literature on attitudes towards old people. Int. J. Nurs. Stud. 22, 171 181.

Inui, T.S., Carter, W.B., Kukull, W.A., Haigh, V.H., 1982. Outcome-Based Doctor-patient Interaction Analysis. Med. Care. $\mathrm{XX}, 535-549$.

Kenny. T., 1990. Erosion of individuality in care of elderly people in hospital-an alternative approach. J. Adv. Nurs. $15,571-576$.

Kerkstra, A., Vorst-Thijssen, T., 1991. Factors related to the use of community nursing services in The Netherlands. J. Adv. Nurs. 16, 47-54.

King, I.M., 1981. A theory for nursing: systems, concepts, process. John Wiley and Sons, New York.

Kihlgren, M., Norberg, A., Brăne, G., Engström, B., Melin, E., 1993. Nurse-patient interaction after training in integrity promoting care at a long-term ward: analysis of video-recorded morning care sessions. Int. J. Nurs. Stud. 30, 1-13.

Lancely, A., 1985. Use of controlling language in the rehabilitation of the elderly. J. Adv. Nurs. 10, 125135.

Levinson, W., Roter, D.L., 1993. The effects of two Continuing Medical Education Programs on Communication Skills of Practicing Primary Care Physicians. J. Gen. Int. Med. 8, 318324.

Liukkonen, A.. 1992. Base care of demented patients living in institutions. J. Clin. Nurs. 1, 345-350.

May, C., 1990. research on nurse patient relationships: problems of theory, problems of practice. J. Adv. Nurs. 15, 307-315.

Miller, A., 1984. Does dependency count? Senior Nurse 1, 1011. 
Moore, J.R., Gilbert, D.A., 1995. Elderly Residents: Perceptions of Nurses' comforting touch. J. Gerontol. Nurs. 21, 6-13

Nyström, A.M., Segesten, K.M., 1996. The family metaphor applied to nursing home life. Int. J. Nurs. Stud. 33, 237-248.

Nolan, M., Grant, G., Nolan, J., 1995. Busy doing nothing: Activity and interaction levels amongst differing populations of elderly patients. J. Adv. Nurs. 22, 528-538.

Oliver, S., Redfern, S.J., 1991. Interpersonal Communication between nurses and elderly patients: refinement of an observation schedule. J. Adv. Nurs. 16, 30-38.

Poole, G., Rowat, K., 1994. Elderly clients' perceptions of caring of a home-care nurse. J. Adv. Nurs. 20, 422-429.

Roter, D., 1989. The Roter method of interaction process analysis. Hopkins University, Baltimore.

Salmon, P., 1993. Interactions of nurses with elderly patients: relationship to nurses' attitudes and to formal activity periods. J. Adv. Nurs. 18, 14-19.
Schepers, G., 1991. Video als feedback-instrument in therapeutische situaties. PhD thesis. Leuven: Katholieke Universiteit.

Staab, A.S., Hodges, L.C., 1996. Essentials of Gerontological Nursing: adaptation to the aging process. J. B. Lippincott Company, Philadelphia.

Sumaya-Smith, I., 1995. Caregiver/resident relationships: surrogate family bonds and surrogate grieving in an skilled nursing facility. J. Adv. Nurs. 21, 447-451.

Verhaak, P.F.M., 1988. Detection of psychological complaints by General Practitioners. Med. Care 26, 1009-1020.

Waters, K.R., 1994. Getting dressed in the early morning: styles of staff/patient interaction on rehabilitation hospital wards for elderly people. J. Adv. Nurs. 19, 239-248. 